\title{
BMJ Open Effects of Iranian healthcare transformation plan on discharge against medical advice rate and related factors in 2012 and 2016
}

\author{
Ali Taghizadieh, ${ }^{1}$ Saber Azami-Aghdash, ${ }^{2}$ Reza Piri, ${ }^{3,4}$ \\ Mohammad Naghavi-Behzad, ${ }^{5,6}$ Hossein Jabbari Beyrami ${ }^{2,7}$
}

To cite: Taghizadieh A, Azami-Aghdash S, Piri R, et al. Effects of Iranian healthcare transformation plan on discharge against medical advice rate and related factors in 2012 and 2016. BMJ Open 2019;9:e024291. doi:10.1136/ bmjopen-2018-024291

- Prepublication history for this paper is available online. To view these files, please visit the journal online (http://dx.doi org/10.1136/bmjopen-2018024291).

Received 19 May 2018 Revised 30 July 2019 Accepted 02 August 2019
Check for updates

(C) Author(s) (or their employer(s)) 2019. Re-use permitted under CC BY-NC. No commercial re-use. See rights and permissions. Published by BMJ.

For numbered affiliations see end of article.

Correspondence to Dr Hossein Jabbari Beyrami; hosseinhosseinj@yahoo.com

\section{ABSTRACT}

Objective Discharge against medical advice (DAMA) is a critical problem in hospitals and has several consequences for healthcare systems. The aim of this study was to determine and compare the rate of DAMA and its related factors before and after executing the healthcare transformation plan (HTP) in Iran.

Methods In a two-phase, cross-sectional study, the DAMA information of 200 patients in 2016 (after HTP) and the patients of a previous study in 2012 (before HTP) was compared. Samples were randomly selected from the main referral centre in the north-west of Iran. Data were collected using a validated and reliable questionnaire and analysed using the SPSS V.16 software.

Results In the post-HTP plan period, the rate of DAMA was $3.9 \%$, while this rate was $5.49 \%$ in $2012(p=0.029)$. A total of $15 \%$ (108 out of 721) of patients in the postreform group and $13.5 \%$ (101 out of 747 ) in the prereform group were rehospitalised $(p=0.411)$. The three main categories of reasons for DAMA in 2012 and 2016 were as follows: patient-related factors, $27 \%$ vs $45 \%$; staff-related factors, $33 \%$ vs $30 \%$; and hospital-related factors (basic amenities), $40 \%$ vs $25 \%$. In both periods, the average scores of patient satisfaction were almost the same; however, satisfaction regarding environmental and human factors in hospitals had changed significantly after HTP $(p<0.05)$.

Conclusions There was a decrease in the rate of DAMA after HTP in Iran. Considering DAMA as a multifactorial phenomenon, this might be due to the higher relative satisfaction after HTP, indicating an increase in public confidence in general hospitals.

\section{INTRODUCTION}

For more than half a century, the issue regarding patients leaving hospitals against medical advice has been discussed in the medical literature. ${ }^{1}$ Discharge against medical advice (DAMA) comes up when a patient (or his/her caregiver) decides to discharge contrary to the opinion of the physician providing medical services. ${ }^{2}$ DAMA is a common problem of hospitals in all countries of the world because it can lead to additional

\section{Strengths and limitations of this study}

- This is the first study designed to determine and compare the rate of discharge against medical advice (DAMA) and its related factors before and after the healthcare transformation plan.

- The limitations of the current study include the low sample size of the population and the absence of matching in the study groups.

- Another limitation is the use of only two time points and one centre as the source of the included patients, which seems insufficient for such a conclusion.

- Another limitation is that because of the general condition of the current hospital containing all specialty and subspecialty departments, the rate of DAMA due to transfer to higher specialty hospital will be lower; therefore, there is a low possibility of transfer of patients from discharge pathway to another more specialised hospital with personal consent.

and unnecessary therapeutic interventions and cost increases of up to $56 \%,{ }^{34}$ morbidity, ${ }^{5}$ rehospitalisation of up to $40 \%$, and even death more than the routine discharge of patients. ${ }^{6}$ It can be considered a service indicator and patient dissatisfaction alarm. ${ }^{7}$

Different studies in the world have indicated a large number of DAMA. For example, DAMA accounted for $1 \%$ of total discharges in Canada, $0.8 \%-2.2 \%$ in the USA, ${ }^{57} 6.2 \%$ in Australia, ${ }^{8} 6 \%$ in Italy, ${ }^{9} 3.3 \%$ in India, ${ }^{10} 4.01 \%$ in Saudi Arabia, ${ }^{11} 0.32 \%$ in Oman, ${ }^{12} 6 \%-8 \%$ in $\operatorname{Iran}^{13}$ and $0.72 \%$ in Nigeria. ${ }^{14}$ Moreover, the rate of DAMA in developing countries is two times higher than in developed countries. $^{15} 16$ In Iranian hospitals, the rate of DAMA is higher compared with similar countries. $^{34}$

Various reasons for DAMA have been mentioned in different studies, including dissatisfaction with hospital services, personal reasons such as addiction or drug abuse, inability to afford payment of hospital bills/ 
costs, psychological problems, family affairs such as taking care of other children at home, lack of significant recovery or feeling of significant recovery after some days of hospitalisation, long-term stay in hospital, and living location (urban or rural). ${ }^{1718}$ As a result of the similarity of the reasons for DAMA in various studies, these reasens can be divided into three different categories: (1) factors related to patients, (2) hospital circumstances (basic amenities) and (3) medical staff. ${ }^{67}$

Studies conducted in Iran have shown the affinity between the reasons for DAMA and healthcare system problems. Therefore, following several reforms in the last decades, such as a strong PHC network and starting family physician programmes with huge achievements, ${ }^{190}$ the hospital-oriented transformation plan was launched in May 2014 in response to varied needs and challenges. ${ }^{21}{ }^{22}$ The main objectives of the plan consist of reducing health expenditure for patients, improving the healthcare services, and increasing coverage as well as access to inpatient care. ${ }^{23}$

By executing the healthcare transformation plan (HTP), there was a decline in direct payments of patients in state hospitals from $37 \%$ to $3 \%$ for rural residents and $6 \%$ for urban ones; all patients were covered by insurance, the incomes of personnel and doctors were noticeably increased, the quality of hospital hotelling services was improved, ${ }^{1324}$ and the number of full-time physicians in public hospitals was increased. ${ }^{13}$ Based on reports, there has been a significant improvement in bed occupancy and turnover, ${ }^{25}$ caesarean delivery, ${ }^{26}$ insurance coverage, ${ }^{22}$ public satisfaction, ${ }^{13}$ hotelling circumstances,${ }^{27}$ hospital functional parameters, ${ }^{28}$ patient admission ${ }^{29}$ and direct payments of patients ${ }^{23}$ after HTP.

Therefore, evaluating the result of the present HTP in Iran is an important necessity for the design of better healthcare reforms in the future. Therefore, the current study was designed to determine and compare the rate of DAMA and its related factors before and after HTP.

\section{MATERIALS AND METHODS}

\section{Study design and settings}

A before-and-after evaluation survey was conducted in the main general educational-medical centre of Tabriz University of Medical Sciences (Tabriz, Iran) in two time periods: before (2012) and after (2016) HTP. This centre is currently the main referral centre in the north-west of Iran, with about 800 inpatient hospital beds, full-service medical specialty and subspecialty, and an average bed occupancy rate of $92.7 \%$.

\section{Study tools and data gathering}

All DAMA patients were considered as the study population, but due to patients' condition (end of life, old age, critical condition, low educational level and other reasons for participation in the study) 200 patients (31\% turnout) were included after exclusion of uncompleted and irrelevant forms in 2012 and 2016 separately. Convenience sampling was applied in the present study and patients who were willing to participate in the study were selected.

The study inclusion criteria were as follows: filling in a written consent form to participate in the study and hospitalisation period between 1 and 30 days at the different departments of the hospital. The study exclusion criteria included hospitalisation for more than a month or less than a day, admission to the emergency medicine department, hospitalisation in the last 1 month, end-stage diseases, missing document components and history of DAMA.

The data collection tool was a questionnaire used by two similar previous studies, ${ }^{3031}$ which contained 29 main factors leading to DAMA, with content validity checked and modified by three specialists. ${ }^{30}{ }^{31}$ As far as some questions were modified, a decision was made to ascertain the validity and reliability of questionnaires one more time. The judgement of 10 experts in specialised fields was used to measure content validity. The correlation between items contained in the questionnaire was evaluated through Cronbach's alpha in order to measure the internal consistency of the questionnaire. The questionnaire's reliability was measured by the test-retest method as well as by the participation of 30 people $(\alpha=0.85)$. The reasons for DAMA were classified into three main categories: personnel-related, hospital-related and patient-related causes. The questionnaires were distributed to patients who were discharged by DAMA and were gathered by two trained researchers.

The study variables consisted of the demographic characteristics of patients, including age, sex, living area, educational level, length of hospital stay (inpatient day), frequency of hospitalisation and type of insurance, as well as parts related to the following:

- Patients' reasons for DAMA, consisting of seven parts: financial problems, dependency of the patient to the family, transfer to other hospital or medical centre, fear of continuing therapy, implicit doctor advice, feeling of recovery, and lack of patient attendant.

- Factors related to personnel, consisting of four parts: proper care of personnel, proper relationships and personnel responsiveness to patients and their attendants, on-time attendance of doctor, and lack of skill and expertise of medical staff.

- Factors related to the hospital (basic amenities), consisting of four parts: accessibility to facilities, crowding, environmental health and hygiene, and nutrition status.

- Total evaluation by patients, consisting of four parts: scoring hospital from 0 to 20, tendency for rehospitalisation in the same hospital in case of need, advising families and relatives to hospitalise in the same hospital in case of need, and direct and indirect costs paid to the hospital.

\section{Statistical analysis}

Data obtained from the study were analysed using descriptive statistics (frequency, percentage, mean and SD). Also, 


\begin{tabular}{|c|c|c|c|}
\hline \multirow[b]{2}{*}{ Characteristics } & \multicolumn{3}{|l|}{ Time period } \\
\hline & Before & After & $P$ value \\
\hline \multicolumn{4}{|l|}{ Gender } \\
\hline Male & $120(60)$ & $130(65)$ & 0.052 \\
\hline Female & $80(40)$ & $70(35)$ & \\
\hline \multicolumn{4}{|l|}{ Living location } \\
\hline Urban & $110(55)$ & $140(70)$ & 0.038 \\
\hline Rural & $90(45)$ & $60(30)$ & \\
\hline Age (years) & $51.82 \pm 23.81$ & $55.16 \pm 21.86$ & 0.172 \\
\hline \multicolumn{4}{|l|}{ Education } \\
\hline Illiterate & $102(51)$ & $92(46)$ & 0.004 \\
\hline Under diploma & $58(29)$ & $5(2.5)$ & \\
\hline Diploma & $23(11.5)$ & $52(26)$ & \\
\hline University degree & $17(8.5)$ & $51(25.5)$ & \\
\hline Length of stay (days) & $6.15 \pm 10.57$ & $6.04 \pm 5.14$ & 0.132 \\
\hline $\begin{array}{l}\text { Frequency of } \\
\text { hospitalisation }\end{array}$ & $1.28 \pm 0.70$ & $1.32 \pm 1.4$ & 0.001 \\
\hline \multicolumn{4}{|l|}{ Type of insurance } \\
\hline Public insurance & $116(58)$ & $156(78)$ & 0.001 \\
\hline Private insurance & $66(33)$ & $19(9.5)$ & \\
\hline No insurance & $18(9)$ & $25(12.5)$ & \\
\hline
\end{tabular}

Data are shown as frequency (percentage) and mean \pm SD. Time period was defined as before and after HTP. DAMA, discharge against medical advice; HTP, healthcare transformation plan.

$\chi^{2}$ and independent-sample t-tests were used to compare the qualitative and quantitative variables between groups, respectively. Statistical analyses were performed using the SPSS V.16.0 software package for Windows. In this study, a $\mathrm{p}$ value of less than $5 \%$ was regarded as statistically significant.

\section{Patient and public involvement}

Patients were not involved because this study included no human participants.

\section{RESULTS}

In this before-after study or quasi-experimental study, 747 (3.9\%) out of 37987 patients were discharged by DAMA in the first half of 2016, while 721 (5.49\%) out of 27468 patients were discharged by DAMA in the first half of $2012(p=029)$. Also, the rehospitalisation rates of DAMA patients were $15 \%$ (108 out of 721 ) and $13.5 \%$ (101 out of 747) after and before HTP, respectively $(\mathrm{p}=0.411)$. Table 1 presents a summary of the demographic characteristics of the included patients in both time periods.

Among hospitalisation wards, gastroenterology, surgery, neurology and thoracic departments were recorded to have the most number of cases of DAMA in both time periods, without any statistical significance $(\mathrm{p}>0.05)$. Table 1 shows
Table 2 Patient-related causes for DAMA before and after HTP

\begin{tabular}{|c|c|c|c|}
\hline \multirow[b]{2}{*}{ Items } & \multicolumn{3}{|c|}{ Time period } \\
\hline & Before & After & $P$ value \\
\hline feeling of recovery & $30(15)$ & $44(22)$ & 0.03 \\
\hline Financial problems & $32(16)$ & $23(11.5)$ & 0.04 \\
\hline $\begin{array}{l}\text { Emotional dependence on } \\
\text { family }\end{array}$ & $34(17)$ & $36(18)$ & 0.79 \\
\hline Afraid of resuming treatment & $22(11)$ & $27(13.5)$ & 0.44 \\
\hline Transfer to another hospital & $22(11)$ & $16(8)$ & 0.3 \\
\hline $\begin{array}{l}\text { Sense of ineffective stay at the } \\
\text { hospital }\end{array}$ & 38 (19) & $36(18)$ & 0.79 \\
\hline Consulting with prior physician & $22(11)$ & $18(9)$ & 0.5 \\
\hline
\end{tabular}

Data are shown as frequency (percentage).

Time period was defined as before and after HTP. DAMA, discharge against medical advice; HTP, healthcare transformation plan.

that there is a significant difference when comparing the educational level $(\mathrm{p}=0.004)$, frequency of hospitalisation $(\mathrm{p}=0.001)$ and coverage of insurance $(\mathrm{p}=0.001)$ between time periods, but with respect to gender, residency area, age and length of stay the difference is not significant ( $p>0.05)$.

According to the reasons mentioned for DAMA, three main categories were elaborated in 2012, namely $27 \%$ of patient-related factors, $33 \%$ of staff-related factors and $40 \%$ of hospital-related factors, while the frequency of these factors was changed to $45 \%, 30 \%$ and $25 \%$ in 2016 , respectively. Patient-related, staff-related and hospital-related reasons for DAMA are shown in tables 2, 3 and 4, respectively.

By comparing factors in patient-related issues (table 2), it was found that the differences in feeling of recovery and financial problems were statistically significant between the two time periods ( $\mathrm{p}=0.03$ and $\mathrm{p}=0.04$, respectively). Moreover, in both time periods, the main factor leading to DAMA was the idea that continuing stay in the hospital would be ineffective, and there was no significant difference between the groups $(\mathrm{p}>0.05)$.

Of the staff-related factors leading to DAMA (table 3 ), important changes include a threefold increase in the proper care of patients by personnel $(23 \%$ vs $66.5 \%$, $\mathrm{p}<0.001)$ and a fourfold increase in doctors' on-time attendance $(p<0.001)$. Furthermore, the difference between parts which evaluated proper relationship with patients and expertise of medical staff was statistically significant ( $\mathrm{p}=0.04$ and $\mathrm{p}=0.002$, respectively).

By comparing the results between the two time periods, with regard to hospital-related factors (table 4), there was a fourfold improvement in patients' nutrition status ( $\mathrm{p}=0.031$ ), but the improvement in hospital sanity was not statistically significant $(\mathrm{p}=0.076)$. Conversely, lack of facilities and crowding had increased significantly ( $\mathrm{p}=0.005$ and $\mathrm{p}=0.03$, respectively). 
Table 3 Staff-related factors affecting DAMA before and after HTP

\begin{tabular}{|c|c|c|c|c|c|c|c|}
\hline \multirow[b]{2}{*}{ Items } & \multirow[b]{2}{*}{ Time period } & \multicolumn{5}{|l|}{ Answers } & \multirow[b]{2}{*}{$P$ value } \\
\hline & & $\begin{array}{l}\text { Absolutely } \\
\text { agree }\end{array}$ & Agree & Neutral & Disagree & $\begin{array}{l}\text { Absolutely } \\
\text { disagree }\end{array}$ & \\
\hline \multirow[t]{2}{*}{ Proper care of personnel } & Before & $25(12.5)$ & $29(14.5)$ & $60(30)$ & $64(32)$ & $22(11)$ & \multirow[t]{2}{*}{$<0.001$} \\
\hline & After & $24(12)$ & $109(54.5)$ & $12(6)$ & 41 (20.5) & $14(7)$ & \\
\hline \multirow{2}{*}{$\begin{array}{l}\text { Lack of proper relationship } \\
\text { and contact with patient }\end{array}$} & Before & $21(10.5)$ & $30(15)$ & $68(34)$ & $60(30)$ & $21(10.5)$ & \multirow[t]{2}{*}{0.04} \\
\hline & After & $12(6)$ & $42(21)$ & $31(15.5)$ & $92(46)$ & $23(11.5)$ & \\
\hline \multirow{2}{*}{$\begin{array}{l}\text { On-time presence of } \\
\text { doctor }\end{array}$} & Before & $8(4)$ & $28(14)$ & $68(34)$ & $70(35)$ & $26(13)$ & \multirow[t]{2}{*}{$<0.001$} \\
\hline & After & $17(8.5)$ & $130(65)$ & $18(9)$ & $35(17.5)$ & $0(0)$ & \\
\hline \multirow{2}{*}{$\begin{array}{l}\text { Lack of skill and expertise } \\
\text { of medical staff }\end{array}$} & Before & $5(2.5)$ & $20(10)$ & $80(40)$ & $73(36.5)$ & $22(11)$ & \multirow[t]{2}{*}{0.002} \\
\hline & After & $1(0.5)$ & $24(12)$ & $36(18)$ & $105(52.5)$ & $34(17)$ & \\
\hline
\end{tabular}

Data are shown as frequency (percentage).

Time period was defined as before and after HTP.

DAMA, discharge against medical advice; HTP, healthcare transformation plan.

In 2016, patients' reports on hospital performance were categorised into weak $(9.5 \%)$, average $(13.5 \%)$, good $(37 \%)$ and excellent $(40 \%)$. The mean total score of patients who evaluated the hospital before and after HTP was $13.82 \pm 4.64$ and $13.43 \pm 4.07$, respectively $(\mathrm{p}=0.37)$.

In the postreform period 138 patients $(69 \%)$ and in the prereform period only 28 patients $(14 \%)$ stated that they would select this hospital again in case of readmission $(\mathrm{p}<0.001)$. Finally, in the postreform period, $68.5 \%$ stated that, in case of a similar problem with their relatives, they would recommend this centre; however, the rate was $54 \%$ for the prereform period.

\section{DISCUSSION}

In this before-after study, the rate of DAMA, the mean length of stay in hospital and the frequency of hospitalisation decreased post-HTP. However, rehospitalisation after hospital discharge increased compared with the prereform period.
According to related studies from 2012 to 2014, the rate of DAMA in different hospital wards (except psychology and emergency wards) in Iran was about 6\%-8\%. ${ }^{732}$ Furthermore, a study of 17 hospitals in Tabriz, Iran resulted in a DAMA rate of $5.7 \% .^{5}$ All these results showed a high rate of DAMA before HTP. However, in a study performed after HTP, this rate was $3.27 \%,{ }^{33}$ which was similar to the results of our study. This improvement could be an indicator of the positive impact of HTP because of the presence of resident physicians at all hours in the hospital, thereby decreasing costs and improving responsiveness. ${ }^{21} 22$

Among the demographic determinants, patients' gender did not show a statistically significant difference in the two time periods. The results of studies conducted by Hwang $e t a l,{ }^{34}$ Moyse and Osman ${ }^{35}$ Vahdat $e t a p^{36}$ were similar to the results of the present study. In these studies, most patients were 60 years old or over, and the mean age of those who were hospitalised was not statistically significant.

Table 4 Hospital-related factors affecting DAMA before and after HTP

\begin{tabular}{|c|c|c|c|c|c|c|c|}
\hline \multirow[b]{2}{*}{ Items } & \multirow[b]{2}{*}{ Time period } & \multicolumn{5}{|l|}{ Answers } & \multirow[b]{2}{*}{$P$ value } \\
\hline & & $\begin{array}{l}\text { Absolutely } \\
\text { agree }\end{array}$ & Agree & Neutral & Disagree & $\begin{array}{l}\text { Absolutely } \\
\text { disagree }\end{array}$ & \\
\hline \multirow[t]{2}{*}{ Hospital hygiene } & Before & $2(1)$ & $24(12)$ & $61(30.5)$ & $80(40)$ & 33 (16.5) & 0.076 \\
\hline & After & $5(2.5)$ & $126(63)$ & $13(6.5)$ & $54(27)$ & $2(1)$ & \\
\hline \multirow[t]{2}{*}{ Lack of facilities } & Before & $4(2)$ & $11(5.5)$ & 75 (37.5) & $80(40)$ & $30(15)$ & 0.005 \\
\hline & After & $5(2.5)$ & $36(18)$ & $20(10)$ & 137 (68.5) & $2(1)$ & \\
\hline \multirow[t]{2}{*}{ Proper nutrition } & Before & $3(1.5)$ & $26(13)$ & $70(35)$ & $74(37)$ & 27 (13.5) & 0.031 \\
\hline & After & $2(1)$ & $111(55.5)$ & $17(8.5)$ & $68(34)$ & $2(1)$ & \\
\hline \multirow{2}{*}{$\begin{array}{l}\text { Lack of satisfaction due } \\
\text { to crowding }\end{array}$} & Before & $7(3.5)$ & $16(8)$ & $64(32)$ & $82(41)$ & $31(15.5)$ & 0.03 \\
\hline & After & $2(2)$ & $48(24)$ & $7(3.5)$ & 139 (69.5) & $4(2)$ & \\
\hline
\end{tabular}

Data are shown as frequency (percentage).

Time period was defined as before and after HTP.

DAMA, discharge against medical advice; HTP, healthcare transformation plan. 
After the transformation plan, insurance coverage increased by $93 \%$ and included 10 million people without using any prior insurance services. ${ }^{24}$ This phenomenon has changed the public tendency towards hospitals and DAMA, as the study of Baptist et $a l^{17}$ showed that both insurance status and household income were associated with an increased risk of DAMA. In addition, the study of Ibrahim $e a^{18}$ showed that having insurance was a predictive factor in DAMA.

The educational level in both periods of studies showed that DAMA is mostly usual among patients with lower educational level. Moreover, in the study of Vahdat $e t a l^{36}$ $55.6 \%$ of DAMA people were illiterate or had under high school education. Furthermore, education level of patients discharged with personal consent was significantly higher in the post-HTP period. In this time the educational level of high school graduates and upper levels had increased from $5.4 \%$ to $55 \%(\mathrm{p}=0.004)$. In a way, this difference showed the tendency of educated people of the society to refer to state hospitals or to rate their dissatisfaction in comparison with low-educated people. This could be due to their higher expectations, leading to hospital discharge. This indicates the higher rate of attendance of people in public hospitals after HTP, which is in accordance with the higher admission rate after HTP and increased number of provided services found in the current study.

This indicates increased demand in public hospitals after HTP, which is in compliance with other studies.

After the reform plan, $70 \%$ of DAMA patients were Tabriz Metropolis residents compared with $55 \%$ of patients before HTP, and this leads to two hypotheses. The first hypothesis is that due to the execution of HTP and the residence of specialist physicians for 24 hours in district hospitals, referral or sending patients to this centre has reduced compared with the pre-HTP period. The second hypothesis is that due to the execution of HTP and various economic-social issues, educated urban people have found a positive attitude towards the hospitals.

Before HTP, hospital-related factors were the most commonly mentioned reasons for DAMA, but after HTP this trend changed such that patient-related factors were the main reasons for DAMA in this study. This was similar to other studies, which indicated a change in hospital-related and patient-related factors.

Personal determinants of DAMA such as economic status, dependence on family, fear of continuing therapy and lack of patient attendant did not show a significant difference; however, the percentage of leaving the hospital due to being emotional was higher in the postreform period (increased from $15.3 \%$ to $22 \%$ ). Among human factors, the part of 'proper care of personnel' showed higher percentage in the post-HTP period, which indicated an increase in patients' satisfaction with the transformation plan. ${ }^{32} 37$

Proper relationships and responsiveness of personnel to patients fail to serve expected quality, probably due to the large number of patients and time constraints, but this issue has not undergone a significant change before and after HTP.
Based on reports of the Ministry of Health and some studies, increased attendance rates of patients at public hospitals after HTP were due to decreased inpatient total payment to hospitals, presence of specialist physicians at all hours and improved facilities, so patients who could not attend hospitals can do now. Patients who visited private hospitals before are now more eager to attend public hospitals.

On-time attendance of doctors at the patient's bedside and the attitude of patients about the proper care of medical staff showed a significant increase post-HTP compared with pre-HTP.

Comparing the environmental factors involved in discharge in the two periods of the study showed satisfaction with environmental hygiene and nutrition status of the hospital, while dissatisfaction with crowding and noise in the hospital environment showed a significant change in comparison with pretransformation study. In the study of Rangraze Jedi and Rabiee, ${ }^{6}$ the reasons for leaving the hospital included issues related to the patient, hospital staff and hospital status. Previous studies conducted in Iran considered lack of facilities as the most important factor for patients' dissatisfaction, and concluded that a considerable percentage of patients were dissatisfied with access to nurse-doctors, as well as their service qualities. ${ }^{67}$

The total evaluation of patients using a 0-20 range to rate their subjective satisfaction with hospitals did not show a significant change in the two studies. However, in the post-HTP period, more patients had stated that they would choose this hospital again in case of need. Therefore, after the health reform plan, people showed higher tendency to introduce this hospital to their relatives in case of problems, and in total this might reflect an improvement in service quality.

In previous studies, most of the reasons for DAMA were dissatisfaction with the doctor, advice and referral of doctors to the private sector and lack of hospital facilities, and prolongation of hospitalisation period was the least reason for discharge with personal consent. ${ }^{738} 39$ Accordingly, it is expected that by increasing the financial support provided by HTP, patients are less eager to leave public hospitals compared with private hospitals. Further studies regarding staff recommendation for patients to go to private hospitals are needed.

\section{CONCLUSION}

There was a decrease in the rate of DAMA after the implementation of HTP in Iran. Based on our findings, considering DAMA as a multifactorial phenomenon, the current decrease might be due to the improved financial and logistic support provided by HTP, as well as the subsequent enhanced recovery sensation. Although HTP has decreased the rate of DAMA, some unfavourable indices regarding healthcare satisfaction still exist. The results of the current study demonstrated that the authorities could modify HTP and maximise its effects on DAMA as well as other different aspects of healthcare. Therefore, the 
suggested research themes are continuous surveillance of frequency and factors related to DAMA and analysis of the results in order to modify treatment headquarters of medical universities and specialty hospitals.

\section{Author affiliations}

${ }^{1}$ Tuberculosis and Lung Disease Research Center, Faculty of Medicine, Tabriz University of Medical Sciences, Tabriz, East Azerbaijan, Iran

${ }^{2}$ Tabriz Health Services Management Research Center, Health Management and Safety Promotion Research Institute, Tabriz University of Medical Sciences, Tabriz, Iran

${ }^{3}$ Department of Nuclear Medicine, Odense University Hospital, Odense, Denmark ${ }^{4}$ Research Unit of Clinical Physiology and Nuclear Medicine, Department of Clinical Research, University of Southern Denmark, Odense, Denmark

${ }^{5}$ Department of Clinical Research, University of Southern Denmark, Odense,

Denmark

${ }^{6}$ Student Research Committee, Tabriz University of Medical Sciences, Tabriz, Iran ${ }^{7}$ Department of Community Medicine, School of Medicine, Tabriz University of Medical Sciences, Tabriz, Iran

Contributors HJB, AT, SA-A, RP and MN-B designed the study and were involved in data collection. HJB, SA-A, RP and MN-B participated in statistical analysis and drafted the manuscript. Critical revision was done by HJB, AT, SA-A, RP and MN-B.

Funding The authors have not declared a specific grant for this research from any funding agency in the public, commercial or not-for-profit sectors.

Competing interests None declared.

Patient consent for publication Obtained.

Ethics approval The study protocol was approved by the Ethics Committee of Tabriz University of Medical Sciences (ethical code: Ir.tbzmed.rec.1393.243), which was in compliance with the Helsinki Declaration.

Provenance and peer review Not commissioned; externally peer reviewed.

Data availability statement All data relevant to the study are included in the article or uploaded as supplementary information.

Open access This is an open access article distributed in accordance with the Creative Commons Attribution Non Commercial (CC BY-NC 4.0) license, which permits others to distribute, remix, adapt, build upon this work non-commercially, and license their derivative works on different terms, provided the original work is properly cited, appropriate credit is given, any changes made indicated, and the use is non-commercial. See: http://creativecommons.org/licenses/by-nc/4.0/.

\section{REFERENCES}

1. Garland A, Ramsey CD, Fransoo R, et al. Rates of readmission and death associated with leaving Hospital against medical advice: a population-based study. Can Med Assoc J 2013;185:1207-14.

2. Aliyu ZY. Discharge against medical advice: sociodemographic, clinical and financial perspectives. Int J Clin Pract 2002;56:325-7.

3. Ashrafi E, Nobakht S, Keykaleh MS, Safi Keykaleh M, et al. Discharge against medical advice (Dama): causes and predictors. Electron Physician 2017;9:4563-70.

4. Azami-Aghdash S, Abolghasem-Gorji H, Moradi-joo M, et al. Frequency and causes of discharges against medical advice from hospital cardiac care units of East Azerbaijan, Iran. Journal of Analytical Research in Clinical Medicine 2016;4:90-6.

5. Tabrizi JS, Jafarabadi MA, Ranai A, et al. Discharge against medical advice (Dama) in hospitals of Tabriz, Iran. Journal of Pioneering Medical Sciences 2015.

6. Rangraze Jedi F, Rabiee $R$. What is rate of respect the rights of patients in government hospital in Kashan. Behbood J 2005;9:62-71.

7. Mohseni M, Alikhani M, Tourani S, et al. Rate and causes of discharge against medical advice in Iranian hospitals: a systematic review and meta-analysis. Iran J Public Health 2015;44:902.

8. Aboriginal A. Torres Strait Islander health performance framework: 2008 report: detailed analyses. Canberra: AlHW, 2008.

9. Saia M, Buja A, Mantoan D, et al. Frequency and trends of hospital discharges against medical advice (Dama) in a large administrative database. Ann Ist Super Sanita 2014;50:357-62.

10. Gautam N, Sharma JP, Sharma A, et al. Retrospective evaluation of patients who leave against medical advice in a tertiary teaching care Institute. Indian J Crit Care Med 2018;22.
11. Youssef A. Factors associated with discharge against medical advice in a Saudi teaching hospital. J Taibah Univ Med Sci 2012;7:13-18.

12. Al-Sadoon M, Al-Shamousi K. Discharge against medical advice among children in Oman: a university hospital experience. Sultan Qaboos Univ Med J 2013;13:534.

13. Moradi-Lakeh M, Vosoogh-Moghaddam A. Health sector evolution plan in Iran; equity and sustainability concerns. Int $\mathrm{J}$ Health Policy Manag 2015;4:637-40.

14. Adebowale Adefemi S, Adefemi SA, Adeleke IT. The rate, reasons and predictors of hospital discharge against medical advice among inpatients of a tertiary health facility in north-central Nigeria. American Journal of Health Research 2015;3:11-16.

15. El Malek VA. Alexander $S$ and al Anezi f. discharge against medical advice among children admitted into pediatric wards at Al-Jahra Hospital, Kuwait. Kuwait Medical Journal 2014;46:28-31.

16. Stranges E, Wier L, Merrill C, et al. Hospitalizations in which Patients Leave the Hospital against Medical Advice (AMA), 2007: Statistical Brief\# 78. Rockville (MD): Agency for Health Care Policy and Research (US), 2006.

17. Baptist AP, Warrier I, Arora R, et al. Hospitalized patients with asthma who leave against medical advice: characteristics, reasons, and outcomes. Journal of Allergy and Clinical Immunology 2007;119:924-9.

18. Ibrahim SA, Kwoh CK, Krishnan E. Factors associated with patients who leave acute-care hospitals against medical advice. Am J Public Health 2007;97:2204-8.

19. Majdzadeh R. Family physician implementation and preventive medicine; opportunities and challenges. Int J Prev Med 2012;3:665.

20. Takian A, Doshmangir L, Rashidian A. Implementing family physician programme in rural Iran: exploring the role of an existing primary health care network. Fam Pract 2013;30:551-9.

21. Asadi-Lari M, Sayyari AA, Akbari ME, et al. Public health improvement in Iran--lessons from the last 20 years. Public Health 2004;118:395-402.

22. Arab-zozani M. Health sector evolution in Iran; a short review. Evidence Based Health Policy, Management and Economics 2017;1:193-7.

23. Heshmati B, Joulaei H. Iran's health-care system in transition. The Lancet 2016;387:29-30.

24. (MoHME) MoHaME. Health sector evolution portal.

25. Moradi G, Piroozi B, Safari H, et al. Assessment of the efficiency of hospitals before and after the implementation of health sector evolution plan in Iran based on Pabon LASSO model. Iranian journal of public health 2017;46:389.

26. Aghyousefi A, Amirpour B, Alipour A, et al. Assessment of changes in cesarean indications before and after the implementation of health sector evolution plan in pregnant women referred to Nezam-Mafi Hospital, Shoush, Khoozestan Province in 2013-2014. Pajoohandeh Journal 2016;20:320-6.

27. Piroozi B. Mohamadi Bolban Abad A and Moradi G. assessing health system responsiveness after the implementation of health system reform: a case study of Sanandaj, 2014-2015. Iranian Journal of Epidemiology 2016;11:1-9.

28. Rezaei S, Arab M. Effects of the new health reform plan on the performance indicators of Hamedan university hospitals. Journal of School of Public Health and Institute of Public Health Research 2016;14:51-60.

29. Faridfar N, Alimohammadzadeh K, Seyedin SH. The impact of health system reform on clinical, paraclinical and surgical indicators as well as patients' satisfaction in Rasoul-e-Akram hospital in 2013 to 2014 Razi Journal of Medical Sciences 2016;22:92-9.

30. Bahadori M, Raadabadi M, Salimi M, et al. Discharge against medical advice: a case study in a public teaching hospital in Tehran, Iran in 2012. Glob J Health Sci 2013;5:179-85.

31. Hadadi A, Khashayar P. Karbakhsh M and Vasheghani Farahani A. discharge against medical advice from a Tehran emergency department. Int J Health Care Qual Assur 2016;29:24-32.

32. Noohi K, Komsari S. Nakhaee N and Yazdi Feyzabadi V. reasons for discharge against medical advice: a case study of emergency departments in Iran. Int J Health Policy Manag 2013;1:137-42.

33. Ranjbar Ezzatabadi M, Atashbahar $\mathrm{O}$ and Rafiei O. Factors associated with discharge against medical advice in teaching hospitals: a case study in Iran. International Journal of Healthcare Management 2017:1-6.

34. Hwang SW, Li J, Gupta R, et al. What happens to patients who leave Hospital against medical advice? CMAJ 2003;168:417-20.

35. Moyse HS, Osmun WE. Discharges against medical advice: a community hospital's experience. Canadian Journal of Rural Medicine 2004;9. 
36. Vahdat S, Hesam S, Mehrabian F. Effective factors on patient discharge with own agreement in selected therapeutic training centers of Ghazvin Shahid Rajaei, 2011.

37. Ohanaka EC. Discharge against medical advice. Trop Doct 2002;32:149-51.
38. El Sayed M, Jabbour E, Maatouk A, et al. Discharge against medical advice from the emergency department: results from a tertiary care hospital in Beirut, Lebanon. Medicine 2016;95:e2788.

39. Mohseni Saravi B, Reza Zadeh E, Siamian H, Saravi B, Zadeh E, et al. Discharge against medical advice in the pediatric wards in Booali sina Hospital, Sari, Iran 2010. Acta Inform Med 2013;21:253-6. 